\title{
Dyke-Davidoff-Masson Sendromlu Olguların Değerlendirilmesi
}

\author{
Evaluation of Patientswith Dyke-Davidoff-Masson Syndrome
}

\section{Ozan Koçak}

Eskisehir Osmangazi Üniversitesi Tip Fakültesi, Çocuk Nöroloji Bilim Dalı, Eskişehir, Türkiye
Correspondence: Ozan KOÇAKEskisehir Osmangazi Üniversitesi Tıp Fakültesi, Çocuk Nöroloji Bilim Dalı, Eskişehir, Türkiye e-mail:Ozankocak79@gmail.com Received: 19.05.2020

Accepted: 10.07.2020

Online published: 13.07 .2020

\section{Özet}

Dyke-Davidoff-Masson Sendromu(DDMS) nadir görülen, temel olarak serebralhemiatrofi, karşı tarafta hemipleji/hemiparezi, epilepsi ve mentalretardasyon ile karakterize bir hastalıktır. Etiyolojisine göre akut DDMS ve konjenital DDMS olarak ayrılır. Retrospektif olarak yapılan bu çalısmada çocuk nörolojisi kliniğinde DDMS tanısı ile takip edilen hastaların demografik, klinik ve radyolojik bulgularının sunulması amaçlanmıștır. Çalıșmaya 7 erkek $3 \mathrm{kız}$ olmak üzere 10 hasta dahil edildi. Hastaların yaș ortalaması $8.3 \pm 1.2$ yıldı. Çalışmamızda 8 hasta konjenital DDMS, perinatalserebraliskemisi olan bir hasta ve merkezi sinir sistemi enfeksiyonu geçiren bir hasta olmak üzere toplam 2 hasta ise akut DDMS olarak kabul edildi. Yedi hastada sol, 3 hastada ise sağ serebralhemiatrofi vardı. Yedi hastada hemiatrofi tarafinda ensefalomalazik değişiklikler ve 7 hastada hemiatrofi tarafinda lateralventriküldilatasyonu saptandi. Tüm hastalarda epilepsi vardı ve 5'i dirençli epilepsi hastasıydı. Ortalama DDMS tanısı konulduğu yaş $7 \pm 1.08$ yıl, ilk beyin görüntülemesi yapılan yaş ise $3.4 \pm 1.2$ yıldı. Hastaların ilk beyin görüntüleme yaşları ile DDMS olarak tanı konuldukları yaş arasında yaklaşık 2 kat fark var olması, DDMS' nin bilinirliğinin yeterli olmadığını düşündürmektedir. Hemipleji/hemiparezi, epilepsi ve mentalretardasyonu olan, beyin görüntülemesinde hemiatrofi saptanan hastalarda DDMS mutlaka ön tanılar arasinda yer almalıdır.

Anahtar Kelimeler: Dyke-Davidoff-Masson Sendromu, serebralhemiatrofi, hemipleji, epilepsi

\section{Abstract}

Dyke-Davidoff-Massonsyndrome (DDMS) is characterizedbycerebralhemiatrophy, contralateralhemiplegia/hemiparesis, epilepsyandmentalretardation. Thepurpose of thisretrospectivestudywastoemphasizethedemographic, clinicalandimagingfindings of 10 child (7 boys, 3 girls) with DDMS. Themeanage of thepatientswas $8.3 \pm 1.2$ years. Eight of ourpatientswereconsidered as congenital DDMS. Theremaining 2 patientswereconsidered as congenital DDMS. Inthesepatients, symptomsappearedfollowingpostnatalhypoxicischaemiaandcentralnervoussysteminfection. Seven patients had leftand 3 patients had rightcerebralhemiatrophy. Ipsilaterallateralventriculardilatationandencephalomalaciawereobserved in 7 patients. Allpatients had unilateralhemiparesis / hemiplegiaandmental/motor retardation. Fivepatients had resistantepilepsy. Themeanageforthediagnosis of DDMS was $7 \pm 1.08$ years, andtheinitialbrainimagingagewas $3.4 \pm 1.2$ years. Therewereapproximatelytwotimesthedifferencebetweenthefirstbrainimagingages of patientsandtheage at whichtheywerediagnosed as DDMS. Thissuggeststhattheawareness of DDMS is not sufficient. DDMS should be amongthepreliminarydiagnoses in patientswithhemiplegia / hemiparesis, epilepsy, andmentalretardationandwithhemiatrophy in brainimaging.

Keywords: Dyke-Davidoff-MassonSyndrome, cerebralhemiatrophy, hemiplegia, epilepsy 


\section{Giriş}

Dyke-Davidoff-Masson Sendromu (DDMS) nadir görülen, etiyolojisi tam olarak aydınlatılamamış bir hastalıktır. Epilepsi, hemipleji/hemiparezi, fasiyal asimetri, mentalretardasyon ve konuşma problemleri DDMS'nin tipik bulgularıdır(1). Konjenital ve edinsel formları olan bu sendromun temel olarak fetal, neonatal veya erken çocukluk döneminde meydana gelen beyin hasarı sonucunda geliştiği düşünülmektedir(2,3). Tanısı primer olarak radyolojik bulgulara dayanmakta olup karakteristik radyolojik bulguları; serebralhemiatrofi, aynı tarafta sulkuslarda, ventrikülde ve sisternalarda genişleme, kafatası kalınlaşması ve paranazal sinüslerde havalanma $\operatorname{artışıdır}(2,4,5)$. Hastalığın prognozunun, dirençli epilepsisi olmayan ve hemipleji/hemiparezisi 2 yaşından sonra gelişen hastalarda daha iyi olduğu bildirilmiştir (2). Görüntüleme imkanlarının artması ile daha çok sayıda tanı konulmaya başlanmış olsa da, daha çok vaka sunumları şeklinde yayınlar mevuttur. Bu çalışmada, hastanemizde DDMS tanısı ile takip ettiğimiz 10 hastanın demografik, klinik ve görüntüleme bulguları sunulmuş̧ur.

\section{Metod}

Retrospektif olarak yapılan bu çalışma Eskişehir Osmangazi Üniversitesi Tıp Fakültesi Hastanesi Çocuk Nörolo jisi Polikliniğinde 2012-2016 yılları arasında takip edilen, klinik ve beyin manyetik rezonans görüntüleme bulguları ile DDMS tanısı konulan 10 hastanın demografik, radyolojik ve klinik özellikleri incelendi. Çalışma için Eskişehir Osmangazi Üniversitesi Etik Kurulu'ndan izin alındı. Hastaların yaş ve cinsiyet dağılımları, özgeçmişleri, gebelik ve doğum öyküleri (intranatal, perinatal, doğumsal hastalık, travma, serebrovasküler hastalık), tanı yaşları, ilk bulguları, nöbet yaşı, nöbet tipi, nörolojik muayene, EEG ve görüntüleme incelemeleri (manyetik rezonans görüntüleme-MRG) sorgulandı.

\section{Bulgular}

Hastaların 7'si erkek 3'ü kızdı, erkek kız oranı 2.3/1 olarak bulundu. Hastaların yaş ortalaması $8.3 \pm 1.2$ yıldı. Akut DDMS olarak değerlendirilen 2 hastadan birinde postnatalhipoksikiskemi, diğerinde ise menenjit geçirme öyküsü mevcuttu. Postnatalhipoksikiskemisi olan hasta, ilerlemeyen doğum eylemi ve fetaldistres nedeni sezaryen ile doğmuş ve doğumdan sonra yenidoğan yoğun bakıma alınmıştı. Yatışının 3.günü nöbetleri olan hastanın beyin $M R G$ 'inde sağ henisferde akut iskemi ile uyumlu bulgular saptanmıştı. Menenjit geçirme öyküsü olan hasta ise miadında, normal vajinal yol doğmuştu ve gebelik/doğum sürecinde risk faktörü yoktu. 1 yaşına kadar gelişim basamakları normaldi. Ateş, bilinç değişikliği ve nöbet geçirme nedenleri ile başvurdukları hastanede bakteriyel menenjit tanısı konulmuştu. Takibinde beyin MRG 'inde sol hemisferde akut iskemi ile uyumlu değişiklikler saptanmıştı. Kalan 8 hasta ise hastalık öyküsü veya bulgusu olmadığı için konjenital DDMS olarak kabul edildi. Konjenital DDMS kabul edilen hastaların ailelerinde risk faktörü yoktu ve doğum öyküleri normaldi (Tablo 1). 
Tablo 1. Hastaların klinik ve radyolojik özellikleri

\begin{tabular}{|c|c|c|c|c|c|c|c|c|}
\hline $\begin{array}{c}\text { Has } \\
\text { ta } \\
\text { no }\end{array}$ & $\begin{array}{l}\text { Yaș } \\
(\mathrm{yl})\end{array}$ & Cinsiyet & $\begin{array}{l}\text { Muhtemel } \\
\text { Etiyol oji }\end{array}$ & $\begin{array}{l}\text { Etkilenen } \\
\text { hemisfer }\end{array}$ & Klinik özellikler & $\begin{array}{c}\text { Epile psi } \\
\text { başlangi ci } \\
\text { (yil) }\end{array}$ & $\begin{array}{l}\text { DDMS } \\
\text { tanı yaşı } \\
\text { (yıl) }\end{array}$ & Beyin MRG \\
\hline 1 & 3 & $\mathrm{E}$ & Konjenital & Sol & $\begin{array}{l}\text { Epilepsi, sağ hemipleji, gelişim } \\
\text { geriliği }\end{array}$ & . & 3 & $\begin{array}{l}\text { Sol serebralhemiatrofi, } \\
\text { ensefalomalazisol } \\
\text { ventriküldilatasyonu }\end{array}$ \\
\hline 2 & 5 & $\mathrm{E}$ & Konjenital & Sol & $\begin{array}{l}\text { Epilepsi,sağ hemipleji, gelişim } \\
\text { geriliği }\end{array}$ & 2,5 & 6 & $\begin{array}{l}\text { Sol serebralhemiatrofi, } \\
\text { ensefalomalazi }\end{array}$ \\
\hline 3 & 6 & $\mathrm{E}$ & $\begin{array}{c}\text { Akut } \\
\text { (perinataliskemi) }\end{array}$ & Sağ & $\begin{array}{l}\text { Dirençli epilepsi,sol hemipleji, } \\
\text { gelişim geriliği }\end{array}$ & 0.1 & 3 & $\begin{array}{l}\text { Sağ serebralhemiatrofi, } \\
\text { ensefalomalazi, sağ } \\
\text { ventriküldilatasyonu }\end{array}$ \\
\hline 4 & 6 & $\mathrm{~K}$ & Konjenital & Sağ & $\begin{array}{c}\text { Epilepsi,sol hemipleji, gelişim } \\
\text { geriliği }\end{array}$ & 3 & 5 & $\begin{array}{l}\text { Sağ serebralhemiatrofi, } \\
\text { ensefalomalazi }\end{array}$ \\
\hline 5 & 7 & $\mathrm{~K}$ & $\begin{array}{c}\text { Akut } \\
\text { (Menenjit) }\end{array}$ & Sol & $\begin{array}{l}\text { Dirençli epilepsi,sağ } \\
\text { hemipleji,gelişim geriliği }\end{array}$ & 1 & 4 , & $\begin{array}{l}\text { Sol serebralhemiatrofi, } \\
\text { ensefalomalazi, sol } \\
\text { ventriküldilatasyonu }\end{array}$ \\
\hline 6 & 8 & $\mathrm{E}$ & Konjenital & Sol & $\begin{array}{c}\text { Epilepsi, Hafif MR,sağ } \\
\text { hemipleji, konușma bozukluğu }\end{array}$ & 4 & 7 & $\begin{array}{l}\text { Sol serebralhemiatrofi, sol } \\
\text { ventriküldilatasyonu }\end{array}$ \\
\hline 7 & 9 & $\mathrm{E}$ & Konjenital & Sağ & $\begin{array}{l}\text { Dirençli epilepsi,Hafif MR,sol } \\
\text { hemipleji, konuşma bozukluğu }\end{array}$ & 1 & 9 & $\begin{array}{l}\text { Sağ serebralhemiatrofi, sağ } \\
\text { vent riküldilatasyonu }\end{array}$ \\
\hline 8 & 10 & E & Konjenital & Sol & $\begin{array}{l}\text { Dirençli epilepsi,Ağır MR,sağ } \\
\text { hemipleji, konușma bozukluğu }\end{array}$ & 2 & 9 & $\begin{array}{c}\text { Sol } \\
\text { serebralhemiatrofiensefalom } \\
\text { alazi, sol } \\
\text { ventriküldilatasyonu }\end{array}$ \\
\hline 9 & 13 & K & Konjenital & Sol & $\begin{array}{l}\text { Epilepsi,Hafif MR,konuşma } \\
\text { bozukluğu,sağ hemipleji }\end{array}$ & 13 & 13 & Sol serebralhemiatrofi \\
\hline 10 & 16 & $\mathrm{E}$ & Konjenital & Sol & $\begin{array}{c}\text { Dirençli epilepsi, Ağır MR,sağ } \\
\text { hemiparezi, konuşma } \\
\text { bozukluğu }\end{array}$ & 1 & 11 & $\begin{array}{l}\text { Sol serebralhemiatrofi, } \\
\text { ensefalomalazi, sol } \\
\text { ventriküldilatasyonu }\end{array}$ \\
\hline
\end{tabular}

Sol hemisferi etkilenen 7, sağ hemisferi etkilenen 3 hasta vard1. Tüm hastalarda epilepsi ve unilateralhemiparezi/ hemipleji mevcuttu. 6 hastada jeneralize tonik-klonik (JTK) nöbet, 2 hastada fokal nöbet ve 1 hastada myoklonik nöbet mevcuttu. 4 hastanın EEG' sinde jeneralize epileptik aktivite, 4 hastada sekonderjeneralize olan fokal epileptik aktivite ve 2 hastada fokal epileptik aktivite vardı. Hastaların 5'i dirençli epilepsi hastasıydı. 5 hastada ilk bulgu tek taraflı güçsüzlük, 5 hastada nöbet geçirme idi. Ortalama DDMS tanısı konulduğu yaş
$7 \pm 1.08$ yıldı. Hastaların nöbet veya güçsüzlük nedenleri ile ilk beyin görüntülemesi yapılan yaş $3.4 \pm 1.2$ yıldı.5 yaş üstü hastaların 2'sinde ağır,3'ünde hafif MR vardı konuşmaları geriydi, 5 yaş altı hastaların tamamında motor ve dil gelişimlerinde gerilik mevcuttu. Hastaların tamamına beyin MRG çekilmişti. Yedi hastada sol, 3 hastada ise sağ serebralhemiatrofi, 7 hastada hemiatrofi tarafında ensefalomalazik değişiklikler ve 7 hastada hemiatrofi tarafında hafif ventrikülerdilatasyon, 6 hastada kortikalsulkuslarda genişleme saptandı (Resim 1). 

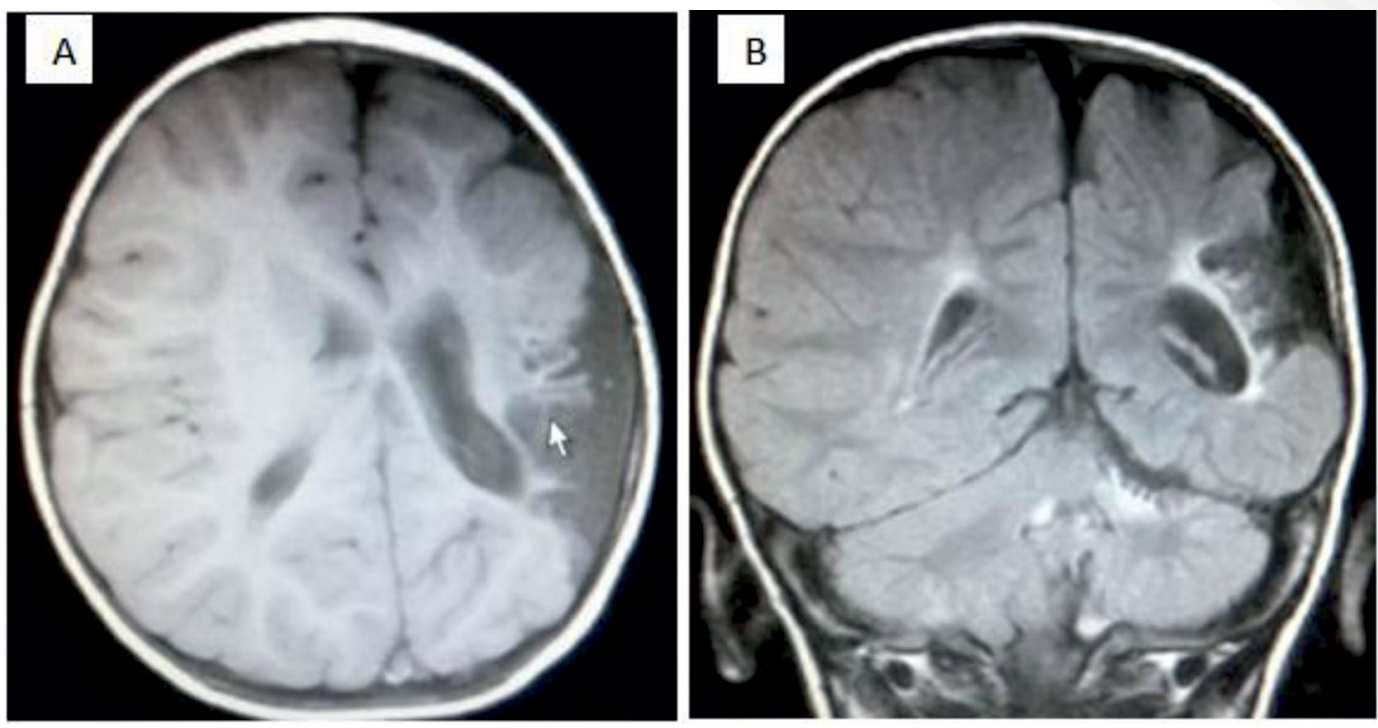

Resim 1. Örnek vaka beyin MRG: A:Aksiyel T1 kesitte sol MCA sulama alanında frontoparietallobtaensefalomalazik alan B:coronal kesittteSupratentorial seviyede sol parietal lobda kortikalsubkortikal alanda kronik iskemikgliotik değişiklikler. Sol serebralhemisfervolümünde azalma, atrofi

\section{Tartışma}

$\mathrm{Bu}$ çalışmada DDMS tanısı ile takip ettiğimiz 10 hastanın klinik, radyolojik ve demografik özellikleri sunulmuştur.

DDMS ilk kez 1933 yılında tanımlanmıștır(4). O dönemden beri genellikle vaka sunumları şeklinde bildirilmiş̧ir. Bildirilen vakalar genellikle nöbet geçirme veya tek taraflı güçsüzlük nedeni ile yapılan beyin görüntülemeleri sonucunda tanı almıştır. Daha önceki çalışmalarda DDMS'nin erkeklerde daha sık görüldüğü raporlanmıştır $(2,6,7,8)$. Ancak Gökçe E. ve arkadaşları (9) çalışmalarında hastalarının \%58.3'ünün kadın olduğunu bildirmiştir. Bizim çalışmamız da literatürle uyumlu olarak erkek hastalar daha fazlaydı (E/K:2,3/1). Etiyolojisi tam olarak bilinmemekle birlikte, konjenital formda; konjenitalmalformasyonlar, enfeksiyon ve serebrovasküler olaylar (orta serebral arterde tıkanma, tek taraflı serebral dolaşım anomalileri), akut formda özellikle yaşamın ilk 3 yllında, hemorajik-iskemikserebrovasküler hastalıklar, doğum asfiksisi, travma, infeksiyonlar ve tümör gibi nedenler sorumlu tutulmuştur $(1,2)$. DDMS'nin başlica görüntüleme bulgusu, diffüz veya fokalserebralhemiatrofi veya serebralhipoplazi ile birlikte ensefalomalazik/gliotik değişikliklerdir. Bunun yanında hemiatrofi ile aynı tarafta sulkuslarda genişleme, ventrikülomegali, paranasal sinüslerde havalanma artışı, kompansatuar kafatasında genişleme ve talamus, lentiformnükleus, kaudatnükleus ve mezensefalondaatrofi görülebilir(2,9). Konjenital DDMS' de edinsel formdan farklı olarak kalvaryal ve fasiyal değişiklikler olabilir. $\mathrm{Bu}$ değişikliklerin hipoplastik beyin dokusunun yarattı̆̆ 1 vakum etkisiyle yaşamın özellikle ilk 3 yılı içinde, kafatası maturasyonunu tamamlamadan geliştiği düşünülmektedir(10,11). Ayrıca DDMS'de daha sık sol hemisferin etkilendiği bildirilmiştir(2,9,12). Bizim çalışmamızda 8 hasta geçirilmiş hastalık öyküsü olmadığı için konjenital DDMS, 2 hasta ise perinatalserebraliskemi ve merkezi sinir sitemi enfeksiyonu tanıları nedeni ile akut DDMS olarak kabul edildi. Literatürle uyumlu olarak hastalarımızın 7' sinde sol hemisferdeatrofi mevcuttu ve hemiatrofi yanında en sık saptanan bulgular ensefalomalazik alanlar ve aynı taraflı ventriküldedilatasyondu. Hastalardaki klasik bulgular değişen derecelerde hemiparezi, hemipleji, nöbet, fasiyal asimetri, konuşma/ dil problemleri, öğrenme bozuklukları ve mentalretardasyondur $(8,12,13)$. 
Konjenital formda hastalarda semptomlaryenidoğan veya süt çocuğu döneminde ortaya çıkarken, akut formda klinik tablonun ortaya çıkması etiyolojik faktörlerin zamanına ve niteliğine göre ileri çocukluk ya da ergenlik dönemine kadar uzayabilir. Nöbeti olmayan ve hemiparezinin 2 yaşından sonra başladığı hastalarda prognozun daha iyi olduğu bildirilmiş̧ir(13). DDMS'da nöbetler genellikle tedaviye dirençlidir. Nöbetler yenidoğan döneminden adolesan döneme kadar geniş bir zaman aralığında başlayabilir. Jeneralize tonik klonik, absans, fokal ve sekonderjeneralize olan nöbetler gibi farklı nöbet tipleri gözlenebilir $(8,14,15)$. Bizim çalışmamızda, 13 yaşında kı hasta, ilk nöbetini geçirmesi nedeni ile getirildiği hastanemizde DDMS tanısı aldı. 5 hastada dirençli epilepsi saptandı ve en sık nöbet tipi JTK nöbetlerdi. Ayrıca hastaların tamamında değişik derecelerde mental ve motor gelişimsel problemler mevcuttu.

DDMS ayırıcı tanıda daha çok unilateralserebralhemiatrofinin görüldüğ̈ SturgeWebersendromu, Rasmussenensefaliti, ensefalokraniokutanözlipomatozis, Silver-Russel sendromu ve lineer nevüs sendromu ve hemimegalensefali düşünülmelidir $(5,10)$. SturgeWebersendromundafasialnevüs ayırt edici özellik olup, mentalretardasyon ve hemipleji görülebilir. Radyolojik olarak serebralhemiatrofi, kalvaryal asimetri, unilateralventriküldilatasyonu ve subaraknoid mesafede genişleme bulunabilir $(9,16)$. Rasmussenensefalit kronik ilerleyici bir inflamatuar hastalıktır. Hemisferikatrofi, epilepsi ve bilişsel fonksiyonlarda bozukluk ile karekterizedir ancak DDMS'de görülen kafatası değişikliklerine rastlanmaz(17).

Lineer nevüssendromu tipik olarak yüzde nevüs, dirençli nöbetler, mentalretardasyon ve serebralhemiatrofiye benzer tek taraflı ventrikülerdilatasyonu ile karakterizedir(2,5,9). Hemimegalensefali; serebralhemihipertrofi ve kortikaldisplazi ile karakterize, nadir görülen bir durumdur. Klinikte tedaviye dirençli epilepsi, ensefalopati ve hemipleji görülebilir (13). Nadir bir nörokutanözsendrom olan ensefalokraniokutanözlipomatozis, tek taraflı kraniyal lipom, hemiatrofi ve kalsifikasyon ile karekterizedir(18). Silver-Russellsendromunda, tipik yüz görünümü(açık alın, üçgen-hipoplazik yüz) ile birlikte serebralhemihipertrofi görülür(19).
Sonuç olarak, Dyke-DavidoffMasson Sendromu nadir görülen, klinik ve radyolojik bulguları birlikte değerlendirildiğinde tanı konulabilen bir hastalıktır. $\mathrm{Bu}$ çalışmada olduğu gibi adolesan döneme kadar tanı alamamış hastalar vardır. Ayrıca bu çalışmada uygun klinik ve beyin görüntüleme bulguları olsa dahi, hastaların DDMS olarak tanı konulma süresinin uzun olduğu görülmüştür, bu da DDMS 'nin bilinirliğinin yeterli olmaması ile açıklanabilir. Sonuç olarak, serebralhemiatrofi, hemiparezi/hemipleji ve/veya dirençli epilepsi bulguları olan hastalarda DDMS hatırlanması gereken hastalıklar arasında olmalıdır. 
1. Chand G, Goel R, Kapur R. Dyke-Davidoff-MassonSyndrome. ArchNeurol. 2010;67:1026.

2. Atalar MH, Icagasioglu D, Tas F. Cerebralhemiatrophy (Dyke-Davidoff-Massonsyndrome) in childhood: clinicoradiologicalanalysis of 19 cases. Pediatric International 2007;49:70-5.

3. Singh P, Saggar K, Ahluwalia A. Dyke-Davidoff-Massonsyndrome: classicalimagingfindings. J Pediatr Neurosci. 2010;5:24-5.

4. Dyke CG, Davidoff LM, Masson CB. Cerebralhemiatrophyandhomolateralhypertrophy of theskullandsinuses. SurgGynecolObstet. 1933;57:588-600

5. Roy U, Panwar A, Mukherjee A, Biswas D. Adultpresentation of dykeDavidoff-Massonsyndrome: a casereport. Case RepNeurol. 2016;8:20-6.

6. Dix JE, Cail WS. Cerebralhemiatrophy: classification on thebasis of MR imagingfindings of mesialsclerosisandchildhoodfebrileseizures. Radiology. 1997;203:26974.

7. Yorulmaz I, Kalaycioglu S, Orguc S, et al. CT and MR imaging of cerebralhemiatrophy (Dyke-Davidoff-Massonsyndrome) cases. Turk. J. Diagn. Interv. Radiol. 1993;3:63-8.

8. Tasdemir HA, Incesu L, Yazicioglu AK, et al. DykeDavidoff-Massonsyndrome. Clin. Imaging. 2002;26:13-7.

9. Gökçe E, Beyhan M, Sade R. Radiologicalimagingfindings of Dyke-Davidoff-Massonsyndrome. ActaNeurolBelg. 2017;117:885-893.

10. Arora R, Rani JY. Dyke-Davidoff-Massonsyndrome: imagingfeatureswithillustration of twocases. QuantImagingMedSurg. 2015;5:469-71.

11. Aguiar $\mathrm{PH}$, Liu CW, Leitao $\mathrm{H}$, et al. MR and CT imaging in theDyke-Davidoff-Massonsyndrome: report of threecasesandcontributiontopathogenesisanddifferentialdiagnosis. ArqNeuropsiquatr. 1998;56:803-7

12. Zeiss J, Brinker RA. MR imaging of cerebralhemiatrophy. J. Comput. Assist. Tomogr. 1988; 12:640-3.

13. Behera MR, Patnaik S, Mohanty AK. Dyke-Davidoff-Massonsyndrome. J NeurosciRuralPract. 2012;3:411-3.

14. Unal O, Tombul T, Cirak B, et al. Lefthemisphereandsexdominance of cerebralhemiatrophy (Dyke-Davidoff-Massonsyndrome). ClinImaging. 2004;28:163-5.
15. Hsinyl, Chuang MF, Shen TW, et al. Temporospatialanalysis define epileptogenicandfunctionalzone in a case of DDMS. Seizure. 2011;20:713-6.

16. Thomas-Sohl KA, Vaslow DF, Maria BL. Sturge-Webersyndrome: a review. Pediatr Neurol. 2004;30:303-10

17. Sheybani L, Schaller K, Seeck M. Rasmussenencephalitis: an update. SchweizArchNeurol. Psychiatr. 2011;162:225-31

18. Kocak O, Yarar C, Carman KB. Encephalocraniocutaneouslipomatosis, a rareneurocutaneousdisorder: report of additionalthreecases. ChildsNervSyst. 2016;32:559-62 19. Wakeling EL, Amero SA, Alders M, et al. Epigenotype-phenotypecorrelations in Silver-Russellsyndrome. J MedGenet. 2010;47:760-8. 